\title{
Osteopontin deficiency enhances anabolic action of EP4 agonist at a sub-optimal dose in bone
}

\author{
Norihiko Kato' ${ }^{1}$, Keiichiro Kitahara ${ }^{1}$, Susan R Rittling ${ }^{2}$, Kazuhisa Nakashima ${ }^{1}$, David T Denhardt ${ }^{3}$, \\ Hisashi Kurosawa ${ }^{4}$, Yoichi Ezura ${ }^{1}$ and Masaki Noda ${ }^{1,5,6,7}$ \\ ${ }^{1}$ Department of Molecular Pharmacology, Medical Research Institute, Tokyo Medical and Dental University, 3-10 Kanda-Surugadai 2-Chome, Chiyoda-ku \\ Tokyo, Tokyo, Japan \\ ${ }^{2}$ Department of Cytokine Biology, The Forsyth Institute, Boston, Massachusetts, USA \\ ${ }^{3}$ Department of Cell Biology and Neuroscience, Rutgers University, Rutgers, New Jersey, USA \\ ${ }^{4}$ Department of Orthopedics, School of Medicine, Juntendo University, Tokyo, Japan \\ ${ }^{5} 21$ st Century Center of Excellence (COE) Program for Frontier Research on Molecular Destruction and Reconstruction of Tooth and Bone, Tokyo, Japan \\ ${ }^{6}$ JSPS Core to Core Program, Japan \\ ${ }^{7}$ Hard Tissue Genome Research Center, Tokyo Medical and Dental University, Tokyo, Japan \\ (Requests for offprints should be addressed to Y Ezura; Email: ezura.mph@mri.tmd.ac.jp; M Noda; Email: noda.mph@mri.tmd.ac.jp)
}

\begin{abstract}
Osteoporosis is one of the most widespread and destructive bone diseases in our modern world. There is a great need for anabolic agents for bone which could reverse this disease, but few are available for clinical use. Prostaglandin E receptor (EP4) agonist (EP4A) is one of the very few anabolic agents for bone in rat, but its systemic efficacy against bone loss at sub-optimal dose is limited in mice. As osteoblasts are regulated by extracellular matrix proteins, we tested whether deficiency of osteopontin (OPN), a secreted phosphorylated protein, could modulate the effects of EP4A (ONO-AE1329) treatment at $30 \mu \mathrm{g} / \mathrm{kg}$ body weight, a sub-optimal dose, for 5 days/week for 4 weeks. OPN deficiency enhanced the anabolic effects of EP4A on bone volume.
\end{abstract}

Histomorphometric analysis indicated that EP4A increased mineral apposition rate as well as bone formation rate in OPN-deficient but not in wild-type mice. Neither OPN deficiency nor EP4A altered osteoclast parameters. Importantly, OPN deficiency enhanced the direct anabolic action of EP4A locally injected onto the parietal bone in inducing new bone formation. Combination of OPN deficiency and EP4A treatment caused an increase in mineralized nodule formation in the cultures of bone marrow cells. Finally, OPN deficiency enhanced anabolic action of EP4A in the mice subjected to ovariectomy. These data indicate that OPN deficiency enhances the actions of EP4A at sub-optimal dose.

Journal of Endocrinology (2007) 193, 171-182

\section{Introduction}

The number of patients with osteoporosis is constantly increasing in the world and this disease has become a major health issue. The increased fracture rate in osteoporotic elderly patients due to reduced bone mass is a major issue in terms of quality of life and economy. Several types of drugs have been developed to treat osteoporosis; most of these are inhibitors of bone resorption (Rodan \& Martin 2000). Effective treatment of osteoporosis, however, requires not only resorption inhibitors, which so far reduce the fracture risk only by $50 \%$, but also stimulators for bone formation especially in patients who already have lost a significant amount of bone mass (Rosen \& Bilezikian 2001). Parathyroid hormone (PTH) has been shown to be an efficacious drug for osteoporosis (Swarthout et al. 2002). However, the peptide nature of $\mathrm{PTH}$ is a problem with respect to its handling and administration. Thus, non-peptide anabolic agents for bone would be an ideal option for the treatment of osteoporosis.

Prostaglandins (PGs) are a group of lipid mediators that are derived from arachidonic acid in a variety of tissues under various physiological and pathophysiological conditions (Narumiya et al. 1999). PGs produced by the cells in the osteoblastic lineage have been shown to play important roles in both bone formation and bone resorption (Pilbeam et al. 2002). Among several PGs, $\mathrm{PGE}_{2}$ exhibits anabolic effects on bone when administered systemically or locally in rat (Yang et al. 1993, Suponitzky \& Weinreb 1998). However, PGE $_{2}$ administration is associated with side effects that include diarrhea, lethargy, and flushing.

Four subtypes of $\mathrm{PGE}_{2}$ receptors, EP1, EP2, EP3, and EP4, have been identified. These receptors are encoded by distinct genes and are expressed differentially in the different tissues (Segi et al. 1998, Ushikubi et al. 1998, Hizaki et al. 1999, 
Narumiya et al. 1999). Previous studies using knockout mice which lack each of the four receptor subtypes revealed that EP4 is the only receptor to mediate the $\mathrm{PGE}_{2}$-induced anabolic action in bone formation (Yoshida et al. 2002, Li et al. 2005). There are a few articles describing that EP2 receptor subtype plays a role in bone formation (Li et al. 2000, 2003, Akhter et al. 2001). It was further demonstrated that administration of an EP4-receptor agonist (EP4A) prevented bone loss in ovariectomized and immobilized rats (Yoshida et al. 2002). EP4A was also shown to restore bone mass in established osteopenic aged rats (Ke et al. 2006). In addition, the systemic administration of EP4A accelerated bone defect healing in the femoral diaphysis after drill-hole injury in mature rats (Tanaka et al. 2004). To our knowledge, there is no previous paper showing that either $\mathrm{PGE}_{2}$ or EP4A exerts a systemic anabolic effect on bone in mice. Both Perry et al. (2000) and Li et al. (2002) show that, in sharp contrast to rats, $\mathrm{PGE}_{2}$ is catabolic in mice for reasons that have not been determined yet. Furthermore, Sasaoka et al. (2004) show that administration of another EP4A into mice has no systemic bone anabolic effect. Thus, in mice, understanding the molecular mechanisms regulating systemic actions of EP4 on bone may contribute to improve the use of EP4A.

Osteoblastic activities are regulated not only by hormones and cytokines but also by extracellular matrix proteins. Osteopontin (OPN) is a non-collagenous bone matrix protein, which is expressed in both osteoblasts and osteoclasts in bone in response to cytokines and mechanical signals to modulate osteoblastic functions as well as osteoclastic functions (Noda \& Denhardt 2002). OPN inhibits mineral crystal growth both in vivo and in vitro (Hunter et al. 1996, Boskey et al. 2002). In vitro experiments revealed that OPN can have conflicting activities. OPN promotes cell attachment by its RGD (arginine, glycine, aspartic acid) motif via binding to integrins (Noda \& Denhardt 2002). This promotion of attachment provides a positive environment for cell growth (Thalmann et al. 1999). Conversely, OPN is a negative regulator of proliferation and differentiation in MC3T3E1 cells (Huang et al. 2004). Thus, the physiological role of OPN in vivo is still not clear based on these in vitro studies, and the elucidation of OPN function especially in vivo is still to be established. Furthermore, although $\mathrm{PGE}_{2}$ regulates OPN expression in vitro, it is not known whether there is a functional relationship between the two molecules. We therefore examined whether OPN deficiency modulates effects of EP4A on bone in vivo using knockout mice.

\section{Materials and Methods}

\section{Animals}

OPN-deficient mice were produced as described by Rittling et al. (1998). The original chimeric mice were backcrossed with 129S1 mice to generate a 129 mixed (S1, S7) background. WT and $\mathrm{OPN}^{-/-}$mice were maintained as separate colonies. To examine the effects of OPN deficiency on EP4 agonist (EP4A), 40 female mice (9-week-old) with either OPN-deficient or wild-type genotype were used for systemic treatment and 16 mice (3-week-old) were used for local treatment. For ovariectomy experiments, 15-week-old mice were used. The mice were housed under controlled conditions on a $12 \mathrm{~h}$ light/12 h darkness cycle and fed with standard laboratory chow and given tap water. The animal experiments were approved by the committee for animal welfare of Tokyo Medical and Dental University.

\section{Experimental protocol}

EP4-receptor agonist (EP4A, ONO-AE1-329; Ono Pharmaceutical Company, Osaka, Japan) was dissolved in saline containing $0 \cdot 3 \%$ ethanol and $0 \cdot 1 \%$ Tween 80 . For systemic treatment, the mice were subjected to s.c. injections in the dorsal flank thrice/day with EP4A at $30 \mu \mathrm{g} / \mathrm{kg}$ body weight or vehicle (saline containing $0 \cdot 3 \%$ ethanol and $0 \cdot 1 \%$ Tween 80) for 5 days/week for 4 weeks. This sub-optimal dose was chosen according to the previous study (Yoshida et al. 2002). To evaluate dynamic bone formation parameters, the mice were injected subcutaneously with $4 \mathrm{mg} / \mathrm{kg}$ calcein, 4 and 2 days before killing. The mice were anesthetized by $150 \mathrm{mg} /$ $\mathrm{kg}$ avertin (tribromoethanol) injection and killed $24 \mathrm{~h}$ after the last EP4A injection.

\section{Body weight of the animals}

To monitor the effects of EP4A on the general body condition of these animals, body weight was measured every day during the experimental periods.

\section{Micro-CT analysis}

The femora were used for three-dimensional micro-CTanalysis. Distal regions of femora were subjected to high-resolution $\mu \mathrm{CT}$ analysis ( $\mu$ CT20, Scano Medical AG, Bassersdorf, Switzerland; Ishijima et al. 2002). Two-dimensional (2D) analysis data were quantified in an area with $0.42 \mathrm{~mm}^{2}(0.7 \times 0.8 \mathrm{~mm})$ in slices $0 \cdot 2 \mathrm{~mm}$ distal to the growth plate of the distal ends of the femora. Some of the femora were also subjected to $2 \mathrm{D} \mu \mathrm{CT}$ analysis using another micro-CT apparatus, Musashi (Nittetsu-ELEX, Osaka, Japan). For cancellous bone of vertebrae, 2D $\mu \mathrm{CT}$ slices were made within a midcoronal plane in the trabecular region of the bones to obtain bone volume/tissue volume (BV/TV) values in a $0.42 \mathrm{~mm}^{2}$ area $(0.7 \times 0.8 \mathrm{~mm})$ of the vertebral bodies. The image data were subsequently quantified using Luzex-F automated image analysis system (Nireco, Tokyo, Japan).

\section{Histomorphometry}

Histomorphometric studies were conducted as described elsewhere according to the definition described by Parfitt et al. (1987). 


\section{RT-PCR}

Total RNA of the whole humerus was extracted according to acid guanidinium thiocyanate-phenol-chloroform method as described (Ishijima et al. 2002). Total RNA (1 $\mu \mathrm{g})$ was used for first strand cDNA synthesis and synthesized cDNA was then subjected to PCR using the following primers: alkaline phosphatase (ALP), forward, $5^{\prime}$-ATTGCCCTGAAACTCCAAAACC- $3^{\prime}$ and reverse, $5^{\prime}$-CCTCTGGTGGCATCTCGTTATC-3'; type 1 procollagen, forward, 5'-TTTGTG GACCTCCGGCTC-3' and reverse, 5'-AAGCAGAGCACTCGCCCT-3'; osterix, forward, $5^{\prime}$-CTGGGGAAAGGAGGCACAAAGAAG- $3^{\prime}$ and reverse, 5'-GGGTTAAGGGGAGCAAAGTCAGAT-3'; and GAPDH, forward, 5'-ACCACAGTCCATGCCATCAC-3' and reverse, 5'-TCCACCACCCTGTTGCTGTA-3'.

\section{Injection of EP4A into calvariae}

EP4A $(30 \mu \mathrm{g} / \mathrm{kg})$ or vehicle was directly injected into calvariae of 3-week-old wild-type and OPN-deficient mice thrice/day for 5 days/week for 4 weeks. Animals were killed 2 days after the last injection into calvariae. Calvariae were removed and were subjected to $\mu \mathrm{CT}$ analysis.

\section{Measurement of serum and urinary parameters of bone metabolism}

Urine was collected from each mouse during the last $24 \mathrm{~h}$ before killing after treatment with EP4A for 4 weeks. Urinary deoxypyridinoline (U-Dpyr) levels were measured using ELISA (Metra Biosystems, Tokyo, Japan). Serum was collected at the final point of killing. ALP in serum was measured (Daiya AUTO T-Alp: Daiya Shiyaku, Tokyo, Japan).

\section{ALP and MTT assay in culture}

Calvariae were harvested after systemic EP4A or vehicle treatment (s.c. injection), and minced pieces (about 1-2 mm in diameter) of the calvariae were placed onto plastic dishes in medium and cultured for 3 weeks to allow outgrowth of the cells. Cells derived from the calvarial outgrowth were harvested and replated in $96-$ well plates $\left(5 \times 10^{4}\right.$ cells/well) and cultured for 8 days. At the end of the cultures, cells were collected for measurement of ALP activity as described previously (Morinobu et al. 2005). The proliferation of calvarial cells was examined based on MTT (3-[4,5dimethylthiazol-2-yl]-2,5-diphenyl tetrazolium bromide) assay (Usui et al. 2002).

\section{Mineralized nodule formation assay}

Bone marrow cells from wild-type and OPN-deficient mice after EP4A or vehicle treatment for 4 weeks were flushed out from tibia and a cell suspension was prepared.
These bone marrow cells were plated in 12-well plates $\left(3.8 \mathrm{~cm}^{2} /\right.$ well $)$ at a concentration of $5 \times 10^{6}$ cells/well in $\alpha$ MEM supplemented with $10 \%$ FBS, $50 \mu \mathrm{g} / \mathrm{ml}$ ascorbic acid, $10 \mathrm{mM} \beta$-glycerophosphate, and antibiotics/antimycotics, with a medium change every 3 days. The culture was continued for 3 weeks in the absence of EP4A or any other drugs in order to examine the effects of EP4A treatment in vivo on osteoblastic activity in vitro. The cultures were fixed with 95\% ethanol for $10 \mathrm{~min}$ and were stained for $10 \mathrm{~min}$ with a saturated solution of alizarin red (Wako, Tokyo, Japan), washed with water, and dried in air. The area of mineralized nodules and total surface of the culture area were measured by using Luzex-F image analyzer. The data were expressed as mineralized nodule area per total culture surface.

\section{Osteoclastogenesis in bone marrow cultures}

Bone marrow cells from wild-type and OPN-deficient mice after treatment with EP4A or vehicle for 4 weeks were flushed out from tibia. The cells were plated in 12 -well plates at $5 \times 10^{6}$ cells/well in $\alpha$-MEM supplemented with $10 \%$ FBS, $10 \mathrm{nM} 1,25(\mathrm{OH})_{2}$ vitamin $\mathrm{D}_{3}$, $100 \mathrm{nM}$ dexamethasone, and antibiotics/antimycotics in the absence of EP4A. Medium was changed every 3 days, and the cells were cultured for 7-9 days. Tartrate-resistant acid phosphatase (TRAP)-positive osteoclast-like multinucleated cells (more than two nuclei) were counted at the end of culture.

\section{Ovariectomy}

For ovariectomy, 15-week-old female wild-type and OPNdeficient mice were used. A total of 24 mice per genotype (WT or $\mathrm{OPN}^{-/-}$) were randomly assigned in equal numbers into sham operation and ovariectomy groups. After surgery, these mice were injected with EP4A at $30 \mu \mathrm{g} / \mathrm{kg}$, thrice/day, 5 days/week for 4 weeks before killing. BV/TV levels were analyzed in a $0.42 \mathrm{~mm}^{2}$ square area located $0.2 \mathrm{~mm}$ away from the growth plate of the distal end of femur.

\section{Statistical analysis}

The results were presented as mean values \pm s.D. Statistical evaluation was performed based on multiple comparison test using Tukey's method. In ovariectomized data, the statistical analysis consisted of $2 \times 2$ factorial analysis of variance (ANOVA) with the factors of operation (sham or ovariectomy) and treatment (control or EP4A). Statistical significance of the main effect of operations and treatments and their interaction was calculated and the $P$ values for interaction were presented. In all tests, $P<0 \cdot 05$ was considered to be statistically significant. 
A Wild type / Cont

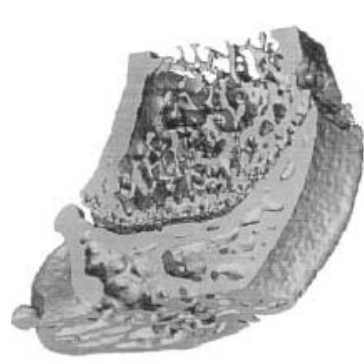

B Wild type / EP4A

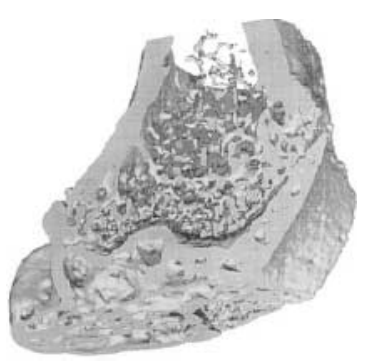

C $\mathrm{OPN}^{-1-} /$ Cont

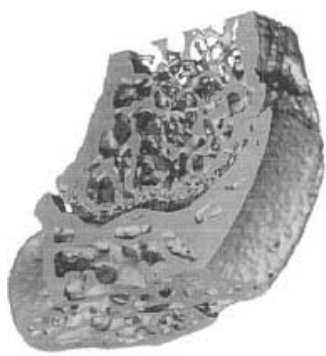

$\mathrm{D} \mathrm{OPN}^{-/-} / \mathrm{EP} 4 \mathrm{~A}$

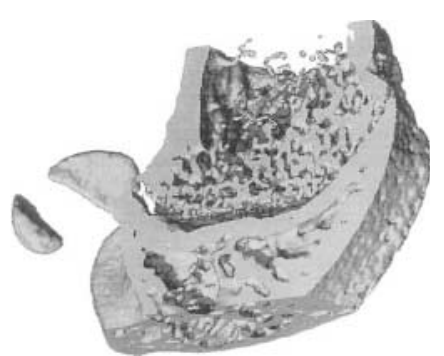

E
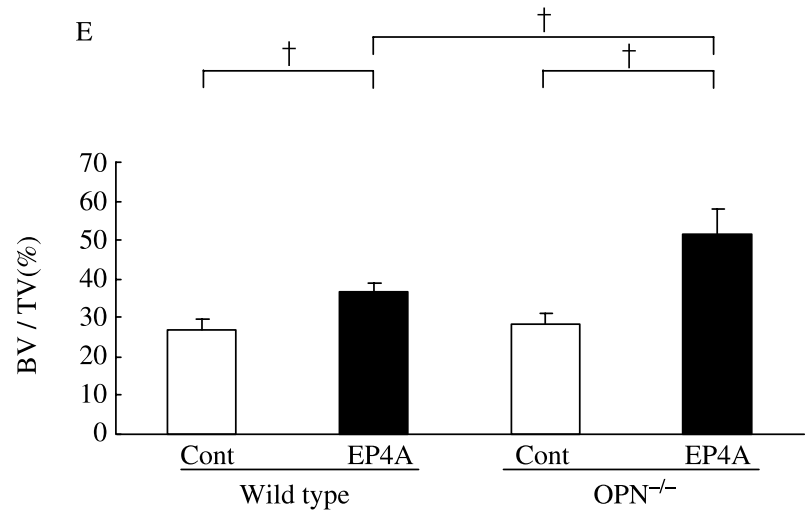

Figure 1 Micro-CT analysis of distal femora. Micro-CT-based reconstruction of distal femora from (A) Wild type/Cont, (B) Wild type/EP4A, (C) $\mathrm{OPN}^{-1-} /$ Cont, and (D) OPN ${ }^{-1-} / \mathrm{EP} 4 \mathrm{~A}$. (E) Bones analyzed for bone volume per tissue volume (BV/TV). Dagger indicates statistically significant difference $\left({ }^{\dagger} P<0 \cdot 01\right)$.

\section{Results}

OPN deficiency angments anabolic effects of EP4A on bone

In order to evaluate the role of the bone matrix protein OPN on anabolic action of EP4 in bone, we examined the structure of bones in WT and OPN-deficient mice treated either with sub-optimal dose of EP4A or vehicle. Micro-CT evaluation indicated that EP4A treatment moderately enhanced the BV/TV in the cancellous bone of the femur in wild-type mice (Fig. 1B versus A and Fig. 1E). In OPNdeficient mice, the vehicle-treated mice had similar bone volume as vehicle-treated wild-type mice (Fig. 1C versus A and Fig. 1E). OPN deficiency enhanced the effects of EP4A on the bone volume more than those in wild-type mice (Fig. 1D versus $B$ and $E$ ).

We further examined whether the enhancement of the anabolic actions of EP4A on cancellous bone by OPN deficiency was limited to the femoral bone or was a general effect on the systemic skeleton. For this purpose, the fourth lumbar vertebrae were subjected to $2 \mathrm{D}$ micro-CT analysis. In wild-type mice, EP4A treatment at sub-optimal dose did not significantly alter the bone volume in the lumbar vertebrae (Fig. 2A versus B and Fig. 2E). The bone volume in lumbar vertebrae of OPN-deficient mice was similar to that in wild-type control or EP4A-treated wild-type mice
(Fig. 2C versus A, B and Fig. 2E). In contrast to wild type, the bone volume in the lumbar vertebrae was significantly increased in OPN-deficient mice treated with sub-optimal dose of EP4A (Fig. 2E, column 4 versus column 2). Thus, OPN deficiency revealed the anabolic actions of EP4A at sub-optimal dose, and this effect was observed at least in two distinct locations.

Previous experiments indicated that $\mathrm{PGE}_{2}$ enhancement of bone formation was associated with a significant loss of body weight and this is an important and serious side effect (Ushikubi et al. 1998). In contrast to these $\mathrm{PGE}_{2}$ effects, neither EP4A treatment at sub-optimal dose nor OPN deficiency altered body weight (Fig. 2F).

To elucidate the target of OPN actions on EP4A effects, we analyzed bone cell activity in vivo. The enhancement of the EP4A-induced increase in BV/TV by OPN deficiency could be due to alterations in bone formation or in bone resorption. To address this point, we conducted histomorphometry to evaluate the dynamic activity of bone formation, i.e. bone mineral apposition rate (MAR) and bone formation rate (BFR). In wild type, MAR was not significantly altered by the treatment with EP4A at sub-optimal dose alone (Fig. 3A). BFR was also not enhanced by EP4A treatment at this dose alone in wild-type mice (Fig. 3B). OPN deficiency alone did not alter MAR (Fig. 3A) nor BFR (Fig. 3B). In contrast, both MAR and BFR were increased in OPN-deficient mice 


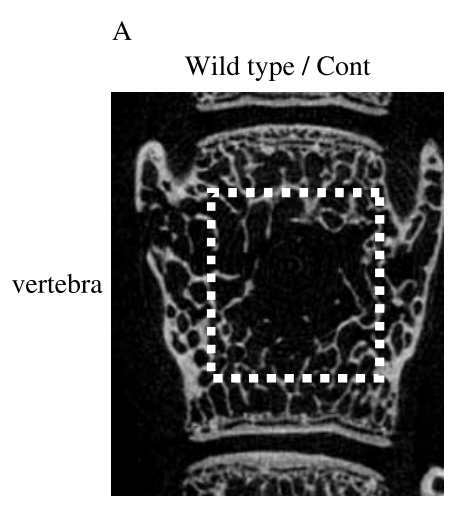

B

Wild type / EP4A

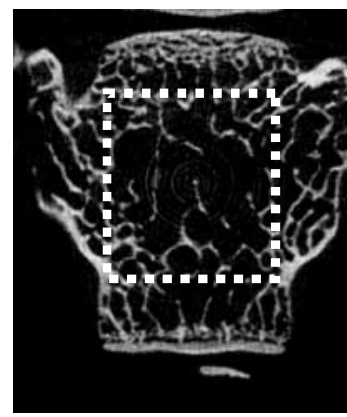

C

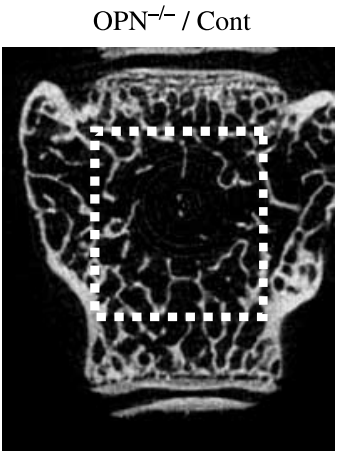

$\mathrm{D}$

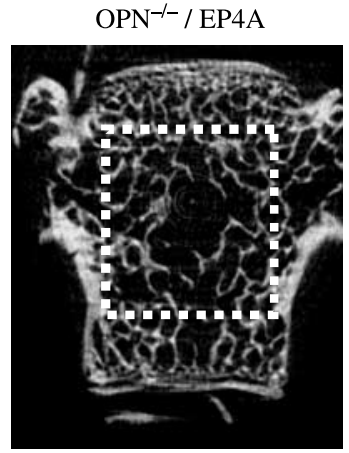

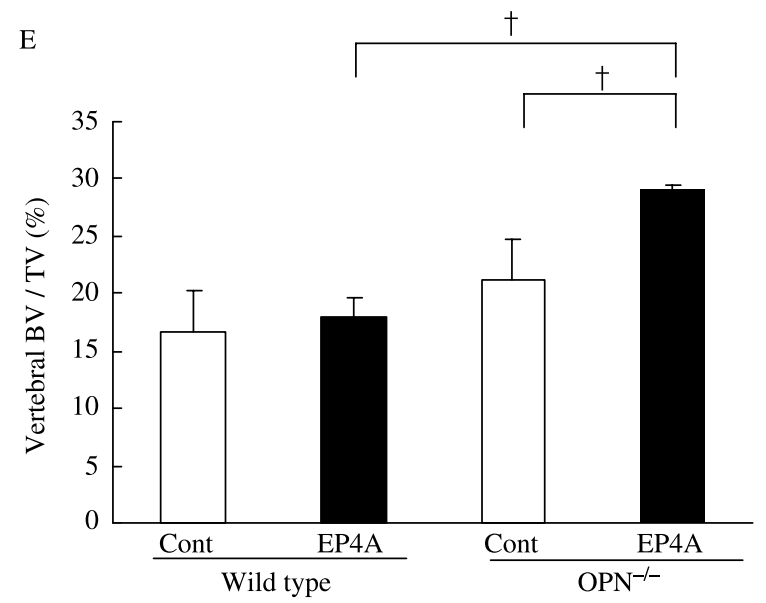

$\mathrm{F}$

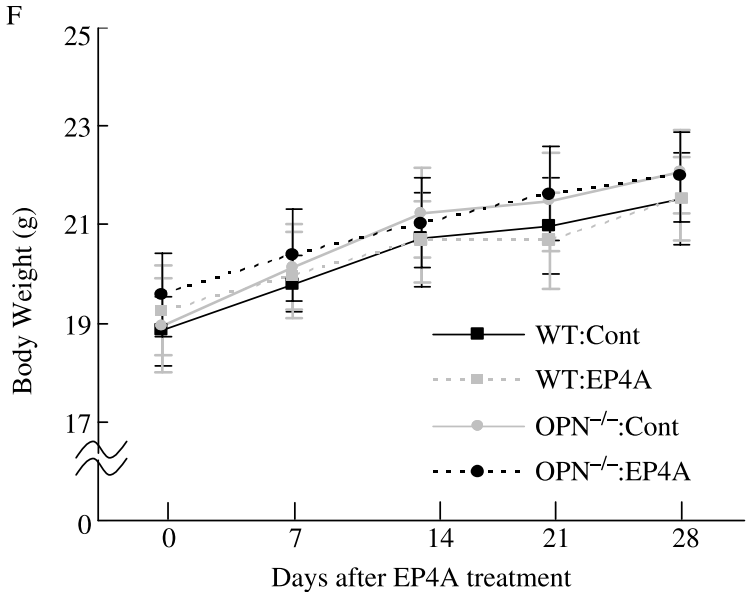

Figure 2 Micro-CT analysis of vertebrae. Micro-CT-based 2D reconstruction of vertebrae of (A) Wild type/Cont, (B) Wild type/EP4A, (C) $\mathrm{OPN}^{-1-} /$ Cont, and (D) OPN ${ }^{-1-} / \mathrm{EP} 4 \mathrm{~A}$. (E) Coronal sections of vertebrae of Wild type/Cont, Wild type/EP4A, OPN ${ }^{-/-} /$Cont, and $\mathrm{OPN}^{-1-} / \mathrm{EP} 4 \mathrm{~A}$ analyzed for bone volume per tissue volume (BV/TV). (F) Body weight during treatment with EP4A or vehicle. Dagger indicates statistically significant difference $\left({ }^{\dagger} P<0 \cdot 01\right)$, Cont, control; WT, wild type.

treated with EP4A at sub-optimal dose (Fig. 3A and B). On the other hand, EP4A at this dose did not alter MS/BS regardless of the genotype (Fig. 3C). Thus, the effects of OPN deficiency on EP4A actions on bone volume were at least in part through its effects on EP4A actions on the bone formation (MAR and BFR) by osteoblasts in vivo.

Since bone histomorphometric analysis provides information only on the morphological aspects of bone, we 

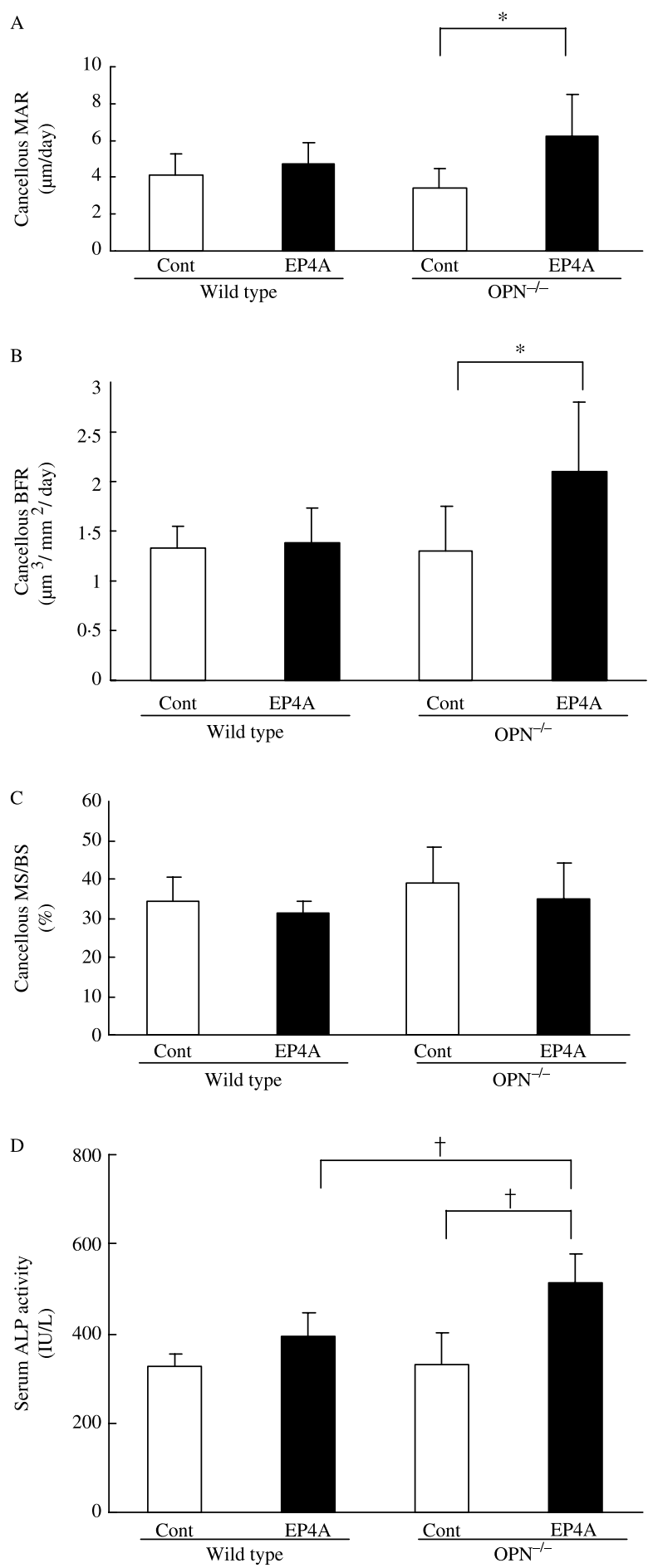

Figure 3 EP4A effects on dynamic histomorphometry on bone formation. (A) MAR, (B) BFR, and (C) MS/BS were measured. (D) EP4A effects on biochemical parameters of bone formation. Serum levels of ALP in Wild type/Cont, Wild type/EP4A, OPN ${ }^{-1-} /$ Cont, and OPN ${ }^{-1} /$ EP4A. Asterisk and dagger indicate statistically significant difference $\left({ }^{*} P<0 \cdot 05,{ }^{\dagger} P<0 \cdot 01\right)$, Cont, control. addressed the question whether the effect of OPN deficiency on EP4A action could be detected based on biochemical (systemic bone formation) parameters. To examine this point, we measured total ALP levels in the serum of the mice. OPN deficiency enhanced more than threefold the EP4A actions on the levels of serum ALP activity (Fig. 3D).

A

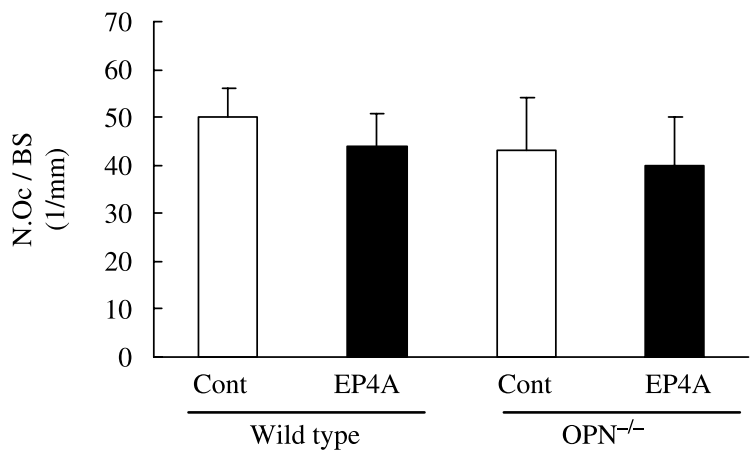

B

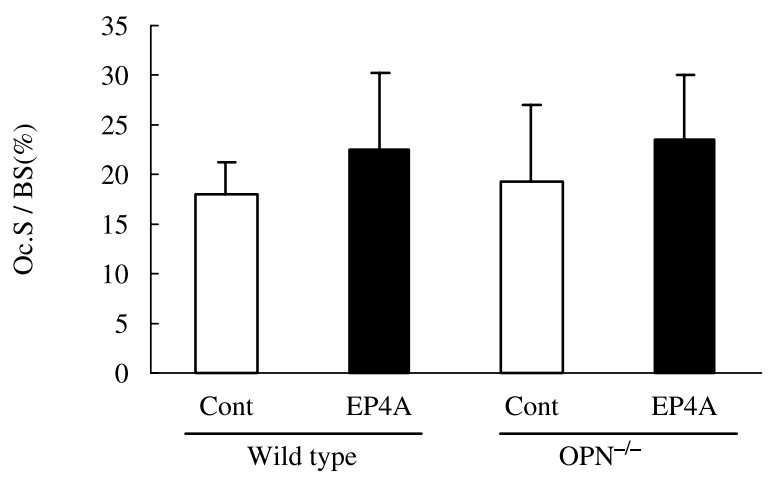

C

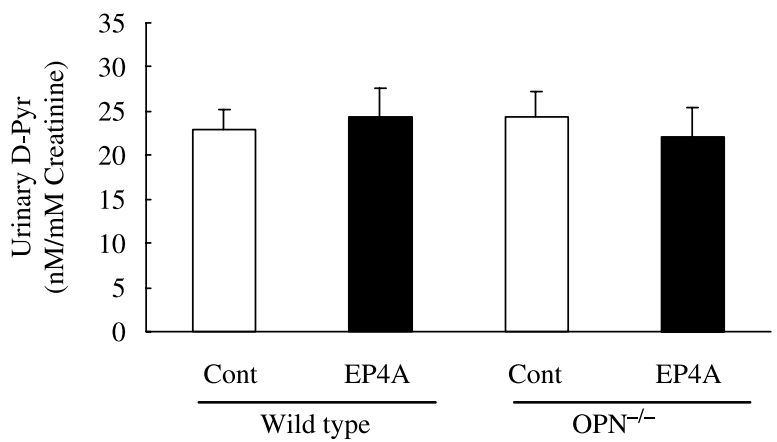

Figure 4 Sections stained for tartrate-resistant acid phosphatase (TRAP) activity. (A) Number of osteoclasts per bone surface (N.Oc/BS) and (B) osteoclast surface per bone surface (Oc.S/BS). (C) Levels of U-Dpyr (see Materials and Methods section), Cont, control.

www.endocrinology-journals.org 
As bone volume is determined not only by bone formation but also by changes in bone resorption, we investigated the effects of OPN deficiency on EP4A action in terms of osteoclastic bone resorption parameters in vivo. Neither EP4A treatment at sub-optimal dose, OPN deficiency, nor a combination of both altered the morphology or number of osteoclasts or the osteoclast surface (Fig. 4A and B). U-Dpyr levels were examined to evaluate the systemic effects on bone resorption. Neither EP4A treatment, OPN deficiency, nor a combination of both altered U-Dpyr secretion compared with the vehicle-treated control in wild type mice (Fig. 4C). These data suggest that the OPN-deficiency enhancement of the suboptimal dose EP4A-induced increase in bone volume was due to the effects on bone formation and not on bone resorption.
A

\section{Wild type / Cont}

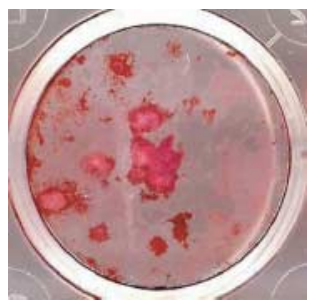

B

Wild type / EP4A

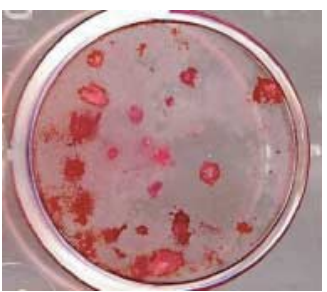

C

$$
\mathrm{OPN}^{-I-} / \mathrm{Cont}
$$

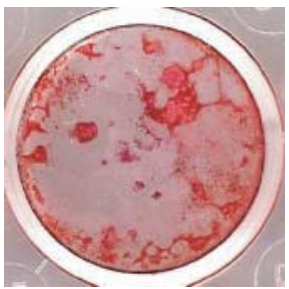

D $\mathrm{OPN}^{-/-} / \mathrm{EP} 4 \mathrm{~A}$

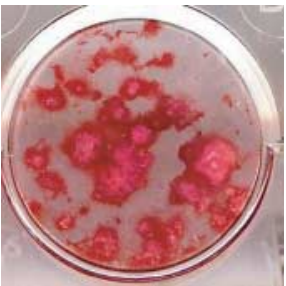

E
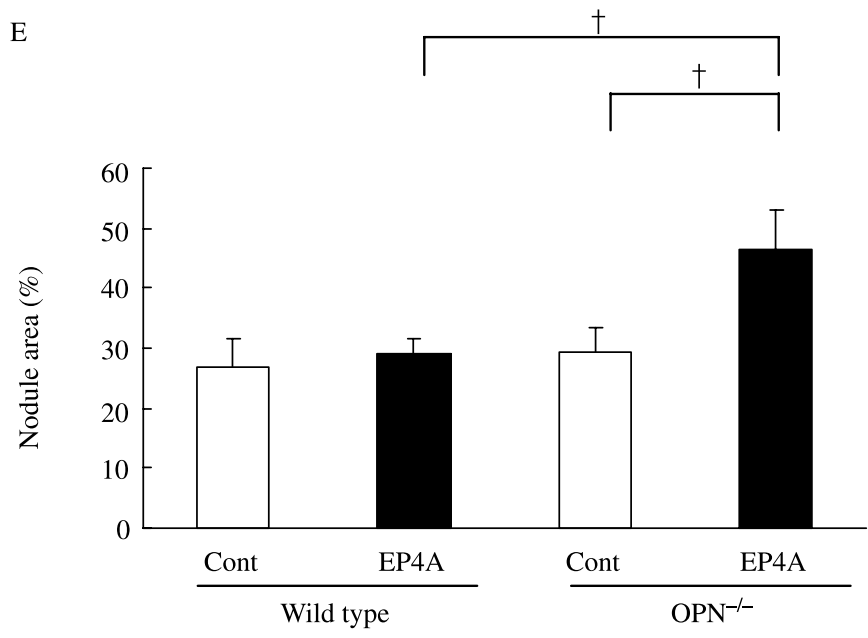

F

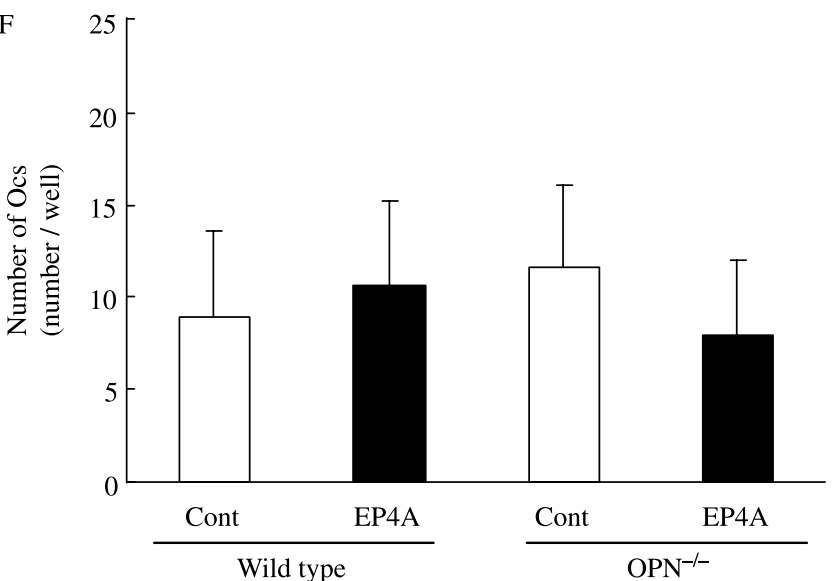

Figure 5 Ex vivo analysis of osteoblast formation and osteoclast formation. (A-D) Mineralized nodule formation in the bone marrow cells obtained from wild-type or OPN-deficient (OPN ${ }^{-1-}$ ) mice after 4 weeks of vehicle (Cont) or EP4 agonist (EP4A) treatment. (E) Quantification of the mineralized nodules. (F) Analysis of osteoclast development: quantitative analysis of number of osteoclasts. ${ }^{\dagger} P<0 \cdot 01$. 
In order to obtain further insights into the mechanisms of OPN-deficiency enhancement of sub-optimal dose EP4A actions in bone, we evaluated osteogenic activity in bone marrow cell cultures by measuring mineralized nodule formation. Sub-optimal dose EP4A treatment in vivo alone did not significantly alter the extent of mineralized nodule formation in bone marrow cells cultured for 3 weeks after the in vivo treatment for 4 weeks (Fig. 5B versus $A$ and Fig. $5 \mathrm{E}$ ). In contrast, OPN deficiency revealed increase in the formation of mineralized nodules in vitro of the cells obtained from EP4Atreated mice (Fig. 5E). Thus, treatment of OPN-deficient mice with EP4A at sub-optimal dose for 4 weeks prior to killing causes an increase in the osteogenic activity in the bone marrow cells. Neither EP4A treatment in vivo, OPN deficiency, nor the combination of both significantly altered the levels of the development of TRAP-positive multinucleated cells in the cultures of the bone marrow cells (Fig. 5F). This again suggests the action of this bone matrix protein to enhance sub-optimal dose EP4A actions on osteoblasts.

To further examine the OPN-deficiency enhancement on EP4A actions in mineralized nodule formation, we used calvaria-derived cells. As described in Materials and Methods, calvariae were removed from mice treated with EP4A or vehicle for 4 weeks in vivo and minced into pieces. These calvarial bone pieces were placed in culture dishes, and about 3 weeks later out-grown cells were harvested from the dishes. These fibroblast-like cells were then replated and cultured for 8 days, and ALP activity was measured. OPN deficiency enhanced the effects of EP4A at sub-optimal dose (administered in vivo) on ALP activity in these calvaria-derived cell cultures (Fig. 6A). Neither OPN deficiency, EP4A treatment in vivo, nor combination of both affected the proliferation of the cells outgrown from the calvariae based on the MTT assay of cells cultured for 3 days (Fig. 6B). These observations further support the notion that OPN deficiency enhanced the actions of EP4A at sub-optimal dose in the cells of osteoblast lineage.

The molecular basis of the ability of OPN deficiency to enhance of EP4A action on cell differentiation was analyzed using PCR-based evaluation of gene expression in the bones of wild-type and OPN-deficient mice treated with EP4A. EP4A treatment at sub-optimal dose alone in vivo did not alter the expression of genes encoding proteins related to osteoblastrelated phenotypes including type I collagen, ALP, and osterix (Fig. 7A-D), while the combination of OPN deficiency and EP4A at sub-optimal dose resulted in elevation of the mRNA expression of these genes (Fig. 7A-D). These data suggest that OPN deficiency enhanced sub-optimal dose EP4A actions in vivo as reflected in the activation of the expression of genes encoding osteoblast phenotype-related proteins.

To address the question whether OPN deficiency enhances direct action of EP4A on bone formation, we directly injected EP4A at sub-optimal dose into the calvariae of mice. Direct EP4A treatment at sub-optimal dose of OPN-deficient mice resulted in more increase in the calvarial thickness than wild type (Fig. 8D versus B and Fig. 8E). Thus, our prior observations on OPN-deficiency enhancement of the sub-optimal dose EP4A effects on bone mass were at least in part due to OPN-deficiency effect on the direct EP4A action on bone.

Finally, we addressed the question whether OPNdeficiency enhancement of EP4A actions could be observed under pathological condition. To examine this point, we conducted ovariectomy experiments in wild-type and OPNdeficient mice. In wild-type mice, ovariectomy reduced the bone volume in the femora as shown previously (Fig. 9A). Treatment with EP4A at sub-optimal dose alone modestly increased trabecular bone volume in sham-operated wildtype mice (Fig. 9A), although the total bone loss was partially resumed by the EP4A treatment of ovariectomized wild-type mice (Fig. 9A, $P=0.362$ ). Thus, EP4A at sub-optimal dose treatment failed to fully prevent bone loss due to ovariectomy compared with sham-operated wild-type mice (Fig. 9A). No interactive effect of ovariectomy on the modest bone massincreasing effect of EP4A was indicated by two-way ANOVA $(P=0 \cdot 395)$. Same experiments were carried out on OPN-deficient mice (Fig. 9B). OPN deficiency alone did not alter the basal levels of bone mass (Fig. 9; comparing column 1 in A and B), while it suppressed the bone loss due to ovariectomy as reported previously (Yoshitake et al. 1999; Fig. 9A). Accordingly, the bone volume in ovariectomized OPN-deficient mice was higher than that in ovariectomized wild-type mice (Fig. 9; comparing column 2 in A and B).

A
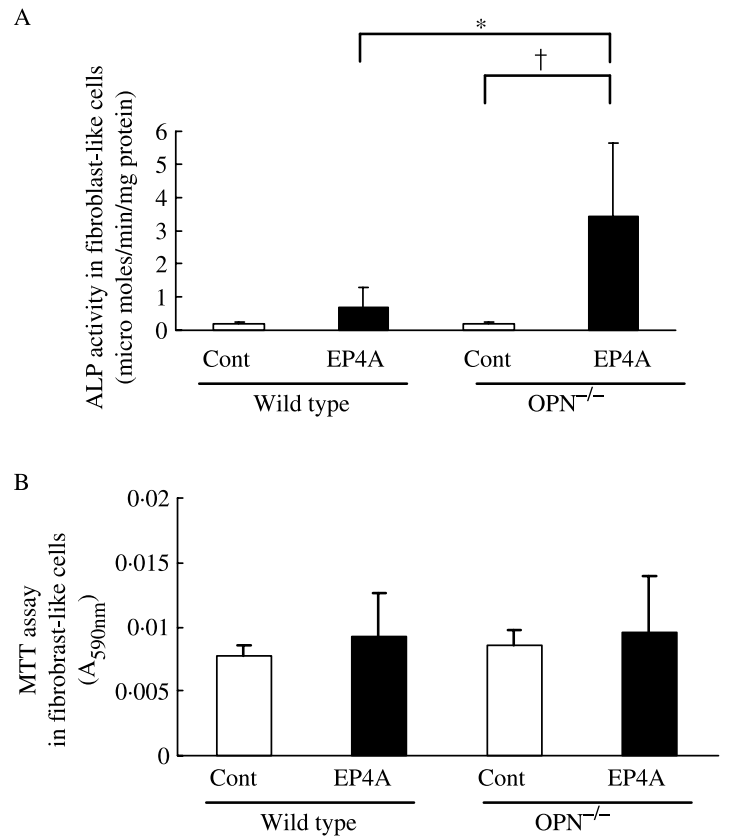

Figure 6 OPN deficiency enhancement of EP4A-induced ALP expression in calvaria-derived cells. (A) Fibroblast-like cells were cultured for 8 days after EP4A treatment for 4 weeks. ALP activities were measured and the values were normalized against protein concentration. (B) Quantitative analysis of proliferation rate (MTT assay) of fibroblast-like cells after culture for 3 days after EP4A treatment for 4 weeks. Asterisk and dagger indicate statistically significant difference $\left({ }^{*} P<0 \cdot 05,{ }^{\dagger} P<0 \cdot 01\right)$, Cont, control. 
A
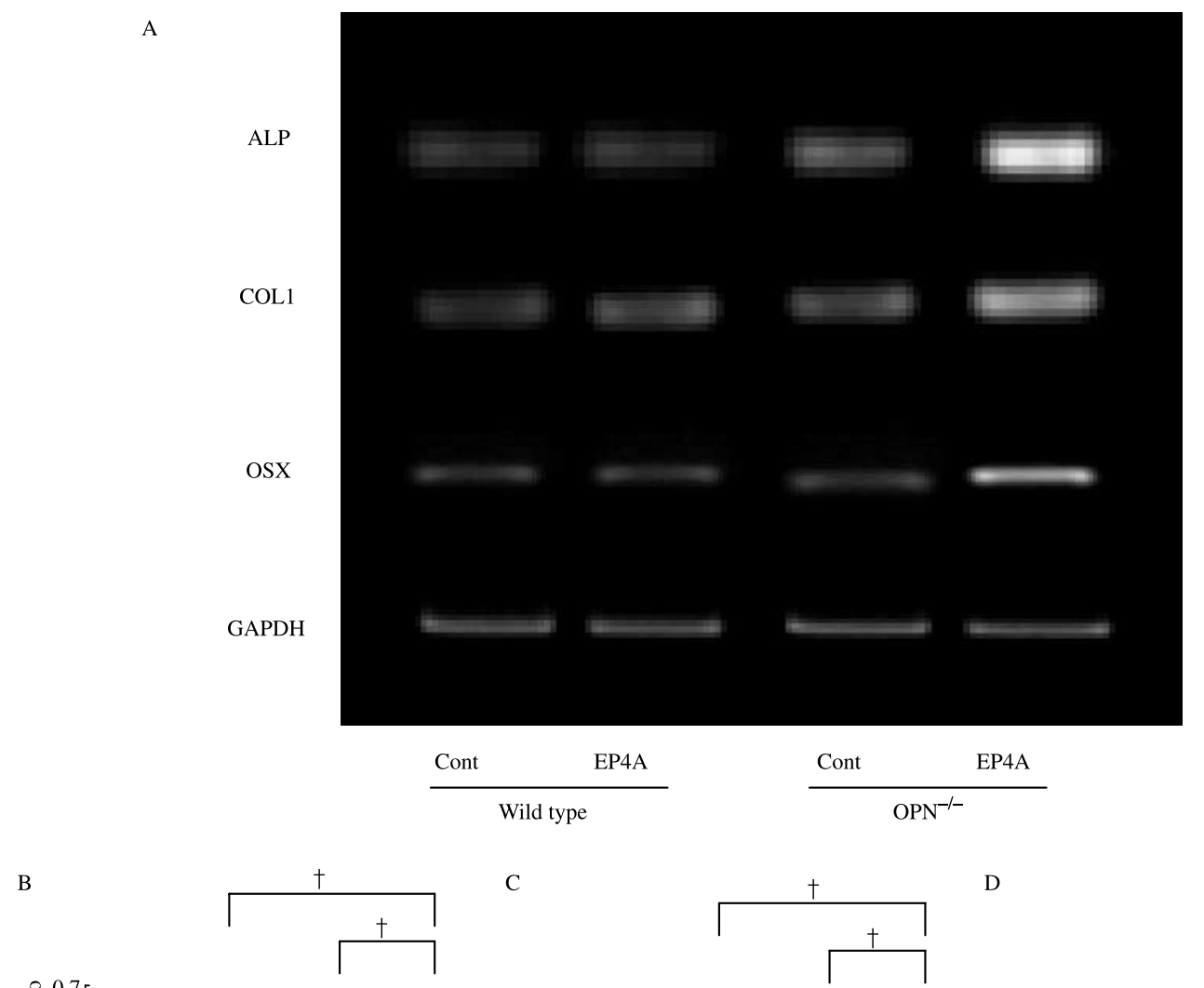

D
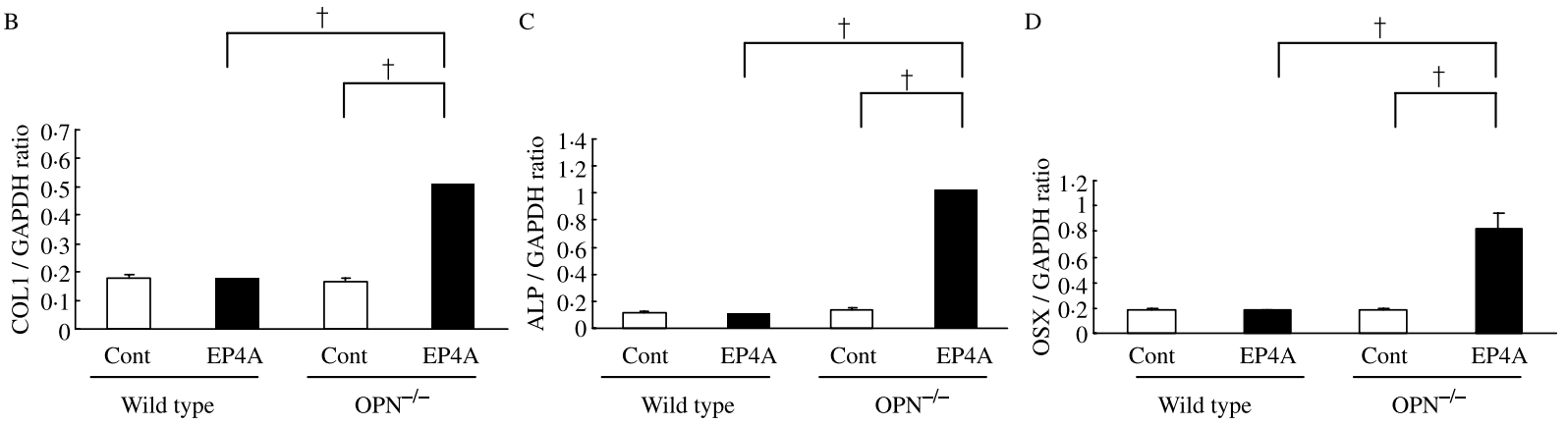

Figure 7 RT-PCR analysis for osterix (OSX), collagen type 1 (COL1), and ALP. (A, B, C, D) Expression levels of COL1 and ALP, and osterix mRNAs in bone enhanced in OPN ${ }^{-1-}$ mice after EP4A treatment. Dagger indicates statistically significant difference $\left({ }^{+} P<0 \cdot 01\right)$, Cont, control.

In this setting, OPN deficiency enhanced EP4A actions in sham-operated mice, as in the previous observations (Fig. 9; comparing columns 1 and 3 in A and B). In addition, OPN deficiency together with sub-optimal dose of EP4A treatment resulted in almost full suppression of bone loss due to ovariectomy (Fig. 9B). Thus, no interactive effect of ovariectomy was indicated again on the significant bone mass increase by EP4A treatment (two-way ANOVA; $P=0.995)$. Most importantly, there was an increase in bone mass following ovariectomy in mice deficient for OPN expression treated with EP4A (Fig. 9B; $P<0 \cdot 01$ ), suggesting that this combination of EP4A and OPN deficiency can preserve and increase bone mass in the absence of estrogen. Neither the effects of OPN deficiency, EP4A treatment, nor the combination of both affected ovariectomy-induced reduction in uterine weight (Fig. 9C).

\section{Discussion}

We observed that OPN deficiency enhanced the otherwise moderate anabolic actions of EP4A at sub-optimal dose in bone. There is no previous paper showing that either $\mathrm{PGE}_{2}$ or EP4A exerts a systemic anabolic effect on bone in mice. As shown in wild-type mice in our experiments, EP4A treatment at sub-optimal dose only moderately prevented bone loss in ovariectomized mice and did not fully restore the levels of bone mass compared with those in wild-type shamoperated mice. In contrast, OPN deficiency enhanced the EP4A-induced increase in bone mass in the ovariectomized mice and fully prevented bone loss due to estrogen depletion. This suggests that release from the inhibitory action of OPN enhanced the moderate anabolic actions of EP4A at suboptimal dose in ovariectomized mice. 


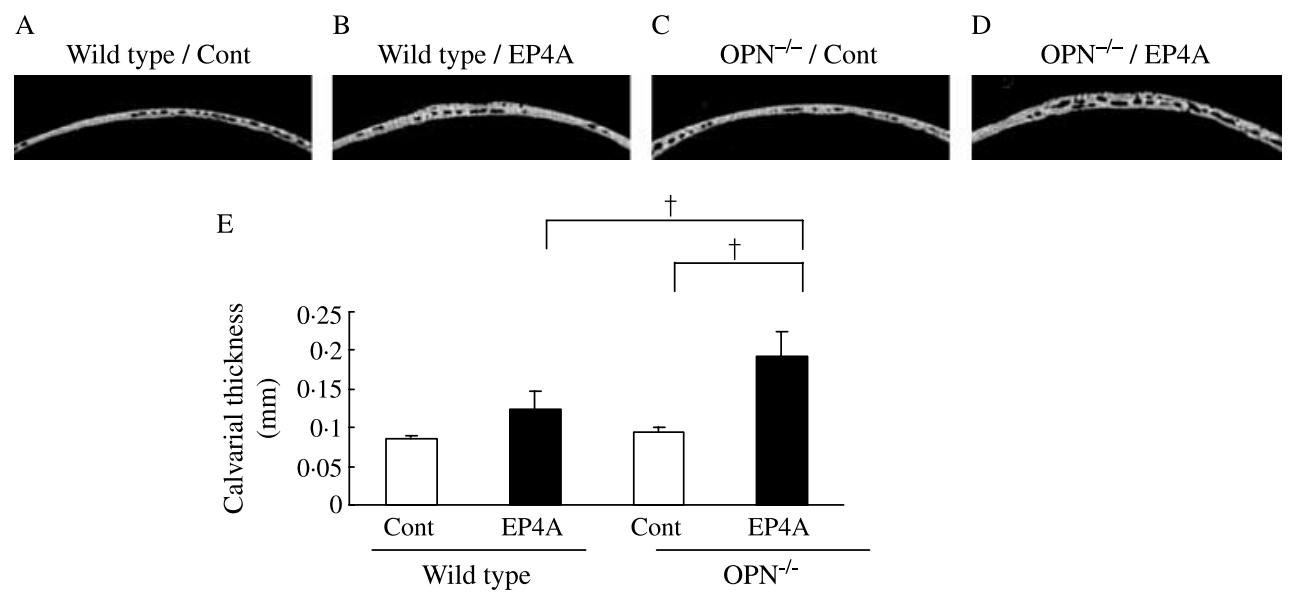

Figure 8 OPN deficiency enhancement of the direct action of EP4A on bone in vivo. (A-D) 2D micro-CT determination of calvarial thickness after local treatment with EP4A. (E) Calvarial thickness in calvarial thickness was calculated as EP4A treated/vehicle. Dagger indicates statistically significant difference $\left({ }^{\dagger} P<0 \cdot 01\right)$, Cont, control.

Our results suggest that differentiation of precursor cells into osteoblasts is enhanced by EP4A together with OPN deficiency, as measured by the accumulation of mineralized nodules in primary osteoblast cultures. These results are consistent with previous work demonstrating that EP4 functions to enhance osteoblast differentiation from precursor cells (Shamir et al. 2004). OPN is a major secretory product of osteoblasts, and is a marker of osteoblastic differentiation, with peak expression occurring during mineralization (Lian \& Stein 1995). OPN would regulate hydroxyapatite formation, inhibiting nucleation in vitro (Pampena et al. 2004) as well as calcification in cell cultures (Jono et al. 2000). Thus, one possible mechanism for the synergistic effect of OPN deficiency and EP4A at sub-optimal dose is an enhancement of osteoblast differentiation, together with release from inhibition of mineralization by OPN. However, this would not simply explain the observations in our experiments. Alternatively, OPN has been implicated in the regulation of hematopoietic stem cells (Nilsson et al. 2005, Stier et al. 2005) and may be involved in osteoblastic differentiation from mesenchymal precursors as well. Knockout mice of another bone matrix protein, osteocalcin, were reported to exhibit higher bone mass than wild type (Ducy et al. 1996). However, the mechanism of osteocalcin deficiency on bone mass control is not known. Whether our observation on OPN may have any relevance to osteocalcin function is still to be elucidated. Understanding the mechanism of the synergistic effect of OPN deficiency and EP4A is an important next step.

PTH has been considered to be one of the promising approaches for preventing fractures more efficiently than the currently used amino bisphophonates. In fact, PTH reduces fracture risks by almost $70 \%$ according to the large multicenter studies (Swarthout et al. 2002). This is more potent than the protection provided by amino bisphosphonates. However, as PTH is a peptide in nature, handling is complex and daily injection is a major problem of this type of treatment.
$\mathrm{PGE}_{2}$ treatment for the patent doctus arteriosus results in bone formation in infants (Jorgensen et al. 1998), and animal studies have revealed the efficacy of $\mathrm{PGE}_{2}$ as a possible bone anabolic agent (Pilbeam et al. 2002). However, the use of $\mathrm{PGE}_{2}$ is limited by its side effects. Most of the early studies using $\mathrm{PGE}_{2}$ indicated that although animals certainly increased their bone mass, they suffered from severe side effects, such as diarrhea and body weight loss (Suponitzky \& Weinreb 1998). Recent reports indicated that the $\mathrm{PGE}_{2}$ receptor EP4 is one of the major receptor subtypes in bone. Therefore, specific EP4As could be used to circumvent side effects of $\mathrm{PGE}_{2}$ (Kabashima et al. 2002). The EP4A has been shown to be efficacious in maintaining bone mass in ovariectomized rats (Yoshida et al. 2002), in increasing ectopic bone mass induced by bone morphogenetic protein (BMP; Sasaoka et al. 2004), and restore bone mass and strength in aged ovariectomized rats (Ke et al. 2006). However, such prevention by EP4A at sub-optimal dose had not yet been demonstrated in mice. Furthermore, there are still concerns due to its possible side effects in organs other than bone which express EP4 receptors (Yoshida et al. 2002). The combination of EP4A at sub-optimal dose and OPN deficiency resulted in increase (Fig. 9B) in bone mass in ovarectomized mice compared with the sham-operated wildtype mice. If one could develop measures to suppress OPN actions in vivo using antibodies, it may be possible to augment the action of EP4A at sub-optimal dose.

EP4A was administered in our experiments through s.c. injection. However, a major strength of this drug is that its structure indicates that it can be effective after oral administration (Yoshida et al. 2002). Thus, compared with PTH, which cannot be administered orally due to its peptide nature, EP4A may be superior in terms of possible clinical oral use in the patients. Several forms of PG drugs have already been used in the clinical setting such as those to increase circulation in the case of obstructive arteritis (Makita et al. 
A

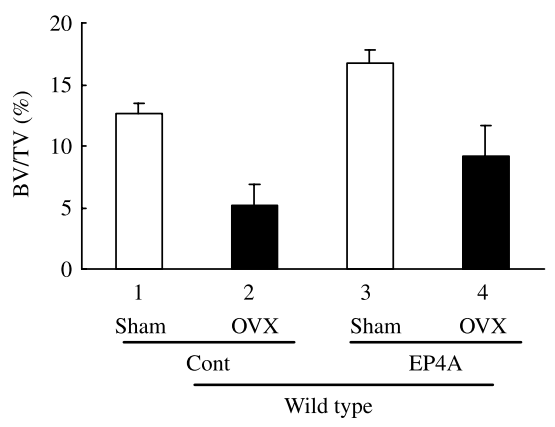

B

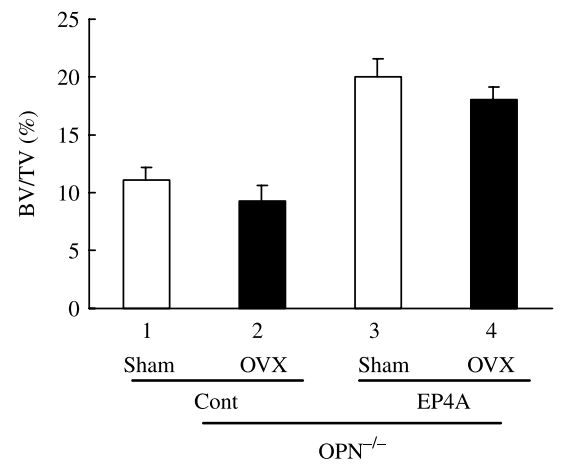

$\mathrm{C}$

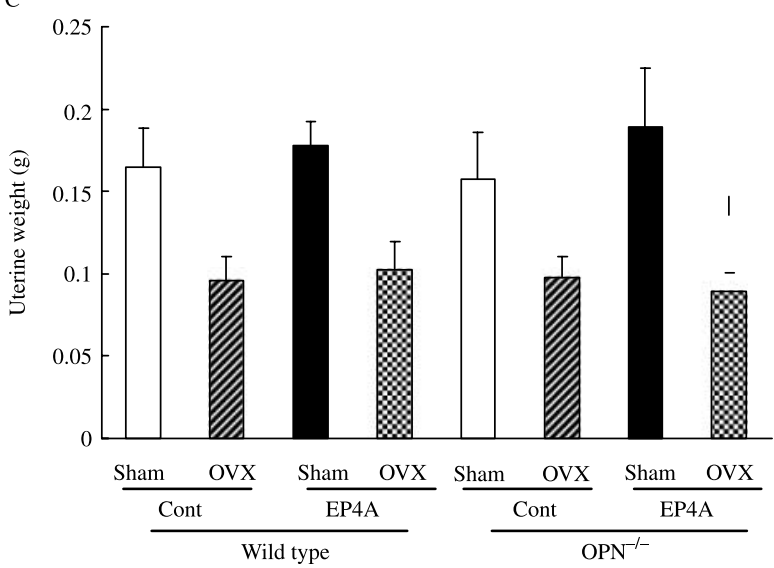

Figure 9 Effects of EP4 signaling induced by OPN deficiency after estrogen depletion. Micro-CT analysis of the femora of mice. MicroCT-based quantification of the BV/TV after ovariectomy $(\mathrm{OVX})$ in (A) EP4A-treated wild-type mice and (B) OPN-deficient mice. (C) Uterine weight by EP4A after ovariectomy in OPN-deficient mice. Interaction between the effects introduced by operations and treatments was tested by $2 \times 2$ factorial ANOVA, Cont, control.

1997) or lumbar canal stenosis (Yone et al. 1999). Together, these observations suggest that orally administrated EP4A may be safe and effective in combination with inhibition of OPN action.

In conclusion, anabolic measures to increase bone mass are among the most important therapies for the osteoporosis patients, especially for those with severe bone loss. However, currently available options such as PTH are not yet regarded as ideal treatment for patients in general, despite its certain efficacy based on evidence. Therefore, efficacious use of nonpeptide compounds will be a breakthrough. Our observation on the OPN-deficiency enhancement of anabolic activity of EP4A at sub-optimal dose may provide a clue to develop novel options for the treatment of osteoporosis.

\section{Acknowledgements}

This research was supported by the grant-in-aid received from the Japanese Ministry of Education (21st Century COE Program, Molecular Destruction and Reconstitution of Tooth and Bone, 17012008, 18109011, 18659438, 18123456) and grants from the Japan Space Forum, NASDA, and the Japan Society for Promotion of Science (JSPS Core to Core Program on Advanced Bone and Joint Science (ABJS), Research for the Future Program, Genome Science). The authors declare that there is no conflict of interest that would prejudice the impartiality of this scientific work.

\section{References}

Akhter MP, Cullen DM, Gong G \& Recker RR 2001 Bone biomechanical properties in prostaglandin EP1 and EP2 knockout mice. Bone 29 121-125. Boskey AL, Spevak L, Paschalis E, Doty SB \& McKee MD 2002 Osteopontin deficiency increases mineral content and mineral crystallinity in mouse bone. Calcified Tissue International 71 145-154.

Ducy P, Desbois C, Boyce B, Pinero G, Strory B, Dunstan C, Smith E, Bonadio J, Goldstein S, Gundberg C et al. 1996 Increased bone formation in osteocalcin-deficient mice. Nature 382 448-452.

Hizaki H, Segi E, Sugimoto Y, Hirose M, Saji T, Ushikubi F, Matsuoka T, Noda Y, Tanaka T, Yoshida N et al. 1999 Abortive expansion of the cumulus and impaired fertility in mice lacking the prostaglandin E receptor subtype EP2. PNAS 96 10501-10506.

Huang W, Carlsen B, Rudkin G, Berry M, Ishida K, Yamaguchi DT \& Miller TA 2004 Osteopontin is a negative regulator of proliferation and differentiation in MC3T3-E1 pre-osteoblastic cells. Bone 34 799-808.

Hunter GK, Hauschka PV, Poole AR, Rosenberg LC \& Goldberg HA 1996 Nucleation and inhibition of hydroxyapatite formation by mineralized tissue proteins. Biochemical Journal 317 59-64.

Ishijima M, Tsuji K, Rittling SR, Yamashita T, Kurosawa H, Denhardt DT, Nifuji A \& Noda M 2002 Resistance to unloadoing-induced threedimensional bone loss in osteopontin-deficient mice. Journal of Bone and Mineral Research 17 661-667.

Jono S, Peinado C \& Giachelli CM 2000 Phosphorylation of osteopontin is required for inhibition of vascular smooth muscle cell calcification. Journal of Biological Chemistry 275 20197-20203.

Jorgensen HRI, Svanholm H \& Host A 1998 Bone formation induced in an infant by systemic prostaglandin-E2 administration. Acta Orthopaedica Scandinavica 59 464-466.

Kabashima K, Saji T, Murata T, Nagamachi M, Matsuoka T, Segi E, Esuboi K, Sugimoto Y, Kobayashi T \& Miyachi Y 2002 The prostaglandin receptor EP4 suppresses colitis, mucosal damage and CD4 cell activation in the gut. Journal of Clinical Investigation 105 469-478.

Ke HZ, Crawford DT, Qi H, Simmons HA, Owen TA, Paralkar VM, Li M, Lu B, Grasser WA, Cameron KO et al. 2006 A nonprostanoid $\mathrm{EP} 4$ receptor selective prostaglandin E2 agonist restores bone mass and strength in aged, ovariectomized rats. Journal of Bone and Mineral Research 21 565-575. 
Li X, Okada Y, Pilbeam CC, Lorenzo JA, Kennedy CR, Breyer RM \& Raisz LG 2000 Knockout of the murine prostaglandin EP2 receptor impairs osteoclastogenesis in vitro. Endocrinology 141 2054-2061.

Li X, Tomita M, Pilbeam CC, Breyer RM \& Raisz LG 2002 Prostaglandin receptor EP2 mediates PGE2 stimulated hypercalcemia in mice in vivo. Prostaglandins and Other Lipid Mediators 67 173-180.

Li M, Ke HZ, Qi H, Healy DR, Li Y, Crawford DT, Paralkar VN, Owen TA, Cameron KO, Lefker BA et al. 2003 A novel, non-prostanoid EP2 receptorselective prostaglandin $\mathrm{E} 2$ agonist stimulates local bone formation and enhances fracture healing. Journal of Bone and Mineral Research 18 2033-2042.

Li M, Healy DR, Li Y, Simmons HA, Crawford DT, Ke HZ, Pan LC, Brown TA \& Thompson DD 2005 Osteopenia and impaired fracture healing in aged EP4 receptor knockout mice. Bone 37 46-54.

Lian JB \& Stein GS 1995 Development of the osteoblast phenotype: molecular mechanisms mediating osteoblast growth and differentiation. Iowa Orthopaedic Journal 15 118-140.

Makita S, Nakamura M, Ohhira A, Itoh S \& Hiramori K 1997 Effects of prostaglandin E1 infusion on limb hemodynamics and vasodilatory response in patients with arteriosclerosis obliterans. Cardiovascular Drugs and Therapy 11 441-448.

Morinobu M, Nakamoto T, Hino K, Tsuji K, Shen ZJ, Nakashima K, Nifuji A, Yamamoto H, Hirai H \& Noda M 2005 The nucleocytoplasmic shuttling protein CIZ reduces adult bone mass by inhibiting bone morphogenetic protein-induced bone formation. Journal of Experimental Medicine 201 961-970.

Narumiya S, Sugimoto U \& Ushikubi F 1999 Prostanoid receptors: structure, properties, and functions. Physiological Reviews 79 1193-1226.

Nilsson SK, Johnston HM, Whitty GA, Williams B, Webb RJ, Denhardt DT, Bertoncello I, Bendall LJ, Simmons PJ \& Haylock DN 2005 Osteopontin, a key component of the hematopoietic stem cell niche and regulator of primitive hematopoietic progenitor cells. Blood 106 1232-1239.

Noda M \& Denhardt DT 2002 Osteopontin. In Principles of Bone Biology, 2 , pp 239-250. Eds JP Bilezikian, LG Raisz \& GA Rodan. San Diego: Academic Press.

Pampena DA, Robertson KA, Litvinova O, Lajoie G, Goldberg HA \& Hunter GK 2004 Inhibition of hydroxyapatite formation by osteopontin phosphopeptides. Biochemical Journal 378 1083-1087.

Parfitt AM, Drezner MK, Glorieux FH, Kanis JA, Malluche H, Meunier PJ, Ott SM \& Recker RR 1987 Bone histomorphometry: standardization of nomenclature, symbols, and units. Report of the ASBMR histomorphometry nomenclature committee. Journal of Bone and Mineral Research 2 595-610.

Perry PV, Crawford DT, Qi H, Ke H \& Pan LC 2000 Systemic prostaglandin E2 administration induces bone loss in mice by a mechanism that requires the EP4 but not the EP2 receptor subtype. Journal of Bone and Mineral Research S224.

Pilbeam CC, Harrison JR \& Raisz LG 2002 Prostaglandins and bone metabolism. In Principles of Bone Biology, 2nd edn , pp 979-994. Eds JP Bilezikian, LG Raisz \& GA Rodan. San Diego: Academic Press.

Rittling SR, Matsumoto HN, McKee MD, Nanci A, An X-R, Novick KE, Kowalski AJ, Noda M \& Denhardt DT 1998 Mice lacking osteopontin show normal development and bone structure but display altered osteoclast formation in vitro. Journal of Bone and Mineral Research 13 1101-1111.

Rodan GA \& Martin TJ 2000 Therapeutic approaches to bone diseases. Science 289 1508-1514.

Rosen CJ \& Bilezikian JP 2001 Clinical review 123: hot topic. Anabolic therapy for osteoporosis. Journal of Clinical Endocrinology and Metabolism 86 957-964.
Sasaoka R, Terai H, Toyoda H, Imai Y, Sugama R \& Takaoka K 2004 A prostanoid receptor EP4 agonist enhances ectopic bone formation induced by recombinant human bone morphogenetic protein-2. Biochemical and Biophysical Research Commununications 318 704-709.

Segi E, Sugimoto Y, Yamasaki A, Aze Y, Oida H, Nishimura T, Murata T, Matsuoka T, Ushikubi F, Hirose M et al. 1998 Patent ductus arteriosus and neonatal death in prostaglandin receptor EP4-deficient mice. Biochemical and Biophysical Research Communications 246 7-12.

Shamir D, Keila S \& Weinreb M 2004 A selective EP4 receptor antagonist abrogates the stimulation of osteoblast recruitment from bone marrow stromal cells by prostaglandin E2 in vivo and in vitro. Bone 34 157-162.

Stier S, Ko Y, Forkert R, Lutz C, Neuhaus T, Grünewald E, Cheng T, Dombkowski D, Calvi LM, Rittling SR et al. 2005 Osteopontin is a hematopoietic stem cell niche component that negatively regulates stem cell pool size. Journal of Experimental Medicine 201 1781-1791.

Suponitzky I \& Weinreb M 1998 Differential effects of systemic prostaglandin E2 on bone mass in rat long bones and calvariae. Journal of Endocrinology 156 $51-57$.

Swarthout JT, D’Alonz RC, Selvamurugan N \& Partridge NC 2002 Parathyroid hormone-dependent singaling pathways regulating genes in bone cells. Gene 282 1-17.

Tanaka M, Sakai A, Uchida S, Tanaka S, Nagashima M, Katayama T, Yamaguchi K \& Nakamura T 2004 Prostaglandin E2 receptor (EP4) selective agonist (ONO-4819.CD) accelerates bone repair of femoral cortex after drill-hole injury associated with local upregulation of bone turnover in mature rats. Bone 34 940-948.

Thalmann GN, Sikes RA, Devoll RE, Kiefer JA, Markwalder R, Klima I, Farach-Carson CM, Studer UE \& Chung LWK 1999 Osteopontin: possible role in prostate cancer progression. Clinical Cancer Research $\mathbf{5}$ 2271-2277.

Ushikubi F, Segi E, Sugimoto Y, Murata T, Matsuoka T, Kobayashi T, Hizaki H, Tuboi K, Katsuyama M, Ichikawa A et al. 1998 Impaired ferbrile response in mice lacking the prostaglandin $\mathrm{E}$ receptor subtype EP3. Nature 395 281-284.

Usui M, Yoshida Y, Yamashita T, Tsuji K, Ishikawa I, Yamamoto T, Nifuji A \& Noda M 2002 Enhancing effect of Tob deficiency on bone formation is specific to bone morphogenetic protein-induced osteogenesis. Journal of Bone and Mineral Research 17 1026-1033.

Yang RS, Liu TK \& Lin-Shiau SY 1993 Increased bone growth by local prostaglandin E2 in rats. Calcified Tissue International 52 57-61.

Yone K, Sakou T \& Kawauchi Y 1999 The effect of lipo prostaglandin E1 on cauda equina bood flow in patients with lumbar spinal canal stenosis: myeloscopic observation. Spinal Cord 37 269-274.

Yoshida K, Oida H, Kobayashi T, Maruyama T, Tanaka M, Katayama T, Yamaguchi K, Segi E, Tsuboyama T, Matsushita M et al. 2002 Stimulation of bone formation and prevention of bone loss by prostaglandin E EP4 receptor activation. PNAS 99 4580-4585.

Yoshitake H, Rittling SR, Denhardt DT \& Noda M 1999 Osteopontindeficient mice are resistant to ovariectomy-induced bone resorption. PNAS $968156-8160$

Received in final form 26 January 2007

Accepted 26 January 2007

Made available online as an Accepted Preprint 26 January 2007 